\title{
SOCIAL ANHEDONIA IS NOT JUST EXTREME INTROVERSION: EMPIRICAL EVIDENCE OF DISTINCT CONSTRUCTS
}

\author{
Elizabeth A. Martin, PhD, David C. Cicero, PhD, \\ Drew H. Bailey, PhD, Nicole R. Karcher, MA, \\ and John G. Kerns, PhD
}

\begin{abstract}
Social anhedonia and introversion, two closely related constructs associated with decreased positive emotions and decreased sociability, are common in schizophrenia-spectrum personality disorders. In light of a myriad of mixed findings regarding positive emotionality in anhedonia, there has been a call to reconceptualize "anhedonia." To clarify the nature of social anhedonia, we used confirmatory factor analysis to investigate the relationship between social anhedonia and introversion. Findings were consistent with the conceptualization of social anhedonia as a separate construct from introversion-the best fitting model was one in which social anhedonia and introversion measures loaded separately. Also consistent with the conceptualization of social anhedonia as separate, we found evidence that it was associated with aspects of alexithymia above and beyond any relationship with introversion. Overall, these results have implications for the understanding of social anhedonia and for the use of it as a discriminating factor between personality disorders characterized by introversion.
\end{abstract}

Social anhedonia refers to reports of diminished experience of positive emotion in response to social stimuli (Horan, Green, Kring, \& Nuechterlein, 2006). It is commonly endorsed among individuals on the schizophrenia (SZ)-spectrum (Andreasen \& Flaum, 1982; Fenton \& McGlashan, 1991), to the extent that it is considered a fundamental pillar of liability for SZ-spectrum disorders (Meehl, 1962; Rado, 1960), such as schizoid, schizotypal, and paranoid personality disorders. Introversion (i.e., low extraversion), a personality factor associated with low positive emotion and low sociability (Costa \& McCrae, 1990; Depue \& Collins, 1999; Goldberg, 1993), is also characteristic of individuals on the SZ-spectrum (Bagby, Parker, \& Taylor, 1994; Berenbaum \& Fujita, 1994; Gurrera, Nestor, \& O’Donnell, 2000). Because social anhedonia and introversion are both characterized by low positive emotion and low sociability, it is unsurprising that they are moderately correlated $(r=.36-.56$;

From Department of Psychology and Social Behavior, University of California, Irvine E. A. M.); Department of Psychology, University of Hawai'i at Manoa (D. C. C.); Department of Education, University of California, Irvine (D. H. B.); and Department of Psychological Sciences, University of Missouri (N. R. K., J. G. K.).

Address correspondence to Elizabeth A. Martin, Ph.D., Social and Behavioral Sciences Gateway, Irvine, CA 92679. E-mail: emartin8@uci.edu 
Cicero \& Kerns, 2010; Kerns, 2006; Martin, Bailey, Cicero, \& Kerns, 2012; Mason, 1995; Ross, Lutz, \& Bailley, 2002). In fact, after removing shared variance with positive schizotypy, another indicator of liability for SZ-spectrum disorders, the association between social anhedonia and introversion is even stronger $(\beta=-.88$; Cicero \& Kerns, 2010). Relatedly, a recent investigation of sociability found that one did not account for variance over the other for a number of indices, suggesting these constructs might not be distinct (Martin et al., 2012). Thus, it is unclear whether social anhedonia is a unique construct or whether it is just extreme introversion.

At the same time, there has been a call to reconceptualize the anhedonia construct (Strauss \& Gold, 2012) because of a myriad of mixed findings related to emotional reports (for reviews, see Cohen \& Minor, 2010; Kring $\&$ Moran, 2008). For example, there is evidence that reports of the experience of positive emotions differ depending on when and in what context they were given (e.g., Gard, Kring, Gard, Horan, \& Green, 2007). Thus, it is not clear if anhedonia is a state-like condition or more of a stable personality trait (Cohen, Najolia, Brown, \& Minor, 2011). The current study aimed to clarify the nature of social anhedonia with respect to introversion, a personality factor with overlapping characteristics.

Social anhedonia in SZ-spectrum disorders is often measured by selfreports and clinician ratings that assess positive emotion about, and details of, social relationships (e.g., interest in relationships, frequency of social contacts). Based on these measures, social anhedonia is considered one of the most intractable symptoms of SZ-spectrum disorders (Grant, Huh, Perivoliotis, Stolar, \& Beck, 2012). Negative symptoms in SZ-spectrum disorders, in particular anhedonia and amotivation (Green, Hellemann, Horan, Lee, \& Wynn, 2012; Kring, Gur, Blanchard, Horan, \& Reise, 2013), are associated with poor outcomes (Blanchard, Mueser, \& Bellack, 1998; Lewandowski et al., 2006). Social anhedonia is evident before the onset of SZ (Häfner et al., 2003) and has been found to predict the onset of SZ-spectrum disorders (Blanchard, Bellack, \& Mueser, 1994; Blanchard et al., 1998; Gooding, Tallent, \& Matts, 2005; Kwapil, 1998). Therefore, a better understanding of social anhedonia could help in the development of new interventions for this treatment-refractory symptom and also provide evidence about the susceptibility of developing SZ-spectrum personality disorders (Lenzenweger, 1999), which could aid in prevention efforts.

Decreased sociability, defined by decreased enjoyment from social activities and increased preference for being alone over being with others (Lucas, Diener, Grob, Suh, \& Shao, 2000) is a prominent feature of social anhedonia (e.g., Kwapil, 1998). There is evidence that individuals with social anhedonia are more likely to be alone and actually prefer to be alone when they are with others (Brown, Silvia, Myin-Germeys, \& Kwapil, 2007; Kwapil, 1998). Further, as levels of social anhedonia increase, people experience more positive emotion and less negative emotion when they are alone (Brown et al., 2007; Kwapil, 1998; Kwapil et al., 2009), but report experiencing less positive emotion and lower positive emotion intensity overall than others (Brown et al., 2007; Gooding, Davidson, Putnam, \& Tallent, 2002; Kerns, Docherty, \& Martin, 2008; Martin, Becker, Cicero, Docherty, \& Kerns, 2011). Thus, a 
general social disinterest, characterized by social withdrawal and isolation, is apparent in social anhedonia (Silvia \& Kwapil, 2011).

Similar to individuals with social anhedonia, people who are high on introversion are often viewed as socially withdrawn and isolated (Hills \& Argyle, 2001). Introversion can be viewed on a continuum with extraversion, a personality factor characterized by high positive emotion and high sociability, among others facets (e.g., Costa \& McCrae, 1990; Goldberg, 1993). By definition, individuals with high levels of introversion are characterized by lower positive emotion (whether alone or with others; Pavot, Diener, \& Fujita, 1990) and preference for solitude or independence from others (Jung, 1928; as cited by Hills \& Argyle, 2001). In addition, extraversion is said to be a more discriminating dimension than neuroticism and agreeableness when using the five-factor model to understand personality disorders, including SZ-spectrum personality disorders (Saulsman \& Page, 2004).

Perhaps unsurprisingly, introversion has been associated with social anhedonia (Cicero \& Kerns, 2010; Kerns, 2006; Mason, 1995; Ross et al., 2002), specifically with the facets of positive emotions and gregariousness (i.e., sociability; Silvia \& Kwapil, 2011). In addition, introversion has been found to be significantly higher in people with SZ-spectrum disorders and those at risk for a spectrum disorder (Bagby et al., 1997; Berenbaum \& Fujita, 1994; Gurrera et al., 2000; Kentros et al., 1997). In fact, when using the five-factor model to conceptualize psychopathology, schizoid personality disorder has been called a disorder of "extreme introversion" (Widiger \& Smith, 2008, p. 750). Also, social anhedonia and introversion are related to similar realworld outcomes, such as being less sociable on a social networking website (Martin et al., 2012).

Given the apparent overlap between social anhedonia and introversionboth theoretically and empirically-it is not clear whether social anhedonia is a unique construct or whether it is just extreme introversion. If social anhedonia is just introversion, these mainly independent, large bodies of literature could be combined to inform theoretical conceptualizations, empirical investigations, and practical applications. The duration of assessments could be reduced. Specifically, the Revised Social Anhedonia Scale (Eckblad, Chapman, Chapman, \& Mishlove, 1982) has 300\% more items than some measures of introversion (40 items vs. 10 items; e.g., Goldberg et al., 2006). Using the shorter introversion measure would decrease the duration of testing for the participant and the time required to compute test scores for the experimenter.

In contrast, if social anhedonia is found to be distinct from, but related to, introversion, this would provide actual empirical support of the treatment of it as a separate construct in the literature. In addition, its consideration could help make diagnostic discriminations between personality disorders. For example, personality psychopathologists could identify disorders characterized by social anhedonia (e.g., schizoid and schizotypal) versus disorders characterized by low extraversion (e.g., avoidant and dependent; Saulsman \& Page, 2004). This is especially relevant given the proposed transition to a more dimensional approach of personality pathology based on the five personality factors detailed in the Diagnostic and Statistical Manual of Mental Disorders, fifth edition (Section III, "Emerging Measures and Models"; American 
Psychiatric Association, 2013). At the same time, given the overlap between these constructs previously reported, the unique aspects of dysfunction in social anhedonia could be identified, which may highlight areas for treatment targets.

One possible factor that might differentiate social anhedonia and introversion is alexithymia, a multifaceted construct characterized by abnormalities in a focus on, identification of, and description of feelings (e.g., Bagby et al., 1994). Although both social anhedonia and introversion are associated with lower trait positive emotion, social anhedonia might have a unique association with alexithymia (e.g., difficulty identifying feelings; less focus on feelings). In support of this, recent research found that in addition to having difficulty identifying their feelings, individuals with social anhedonia report an increased desire to ignore their own emotions, and that they actually ignore emotional stimuli behaviorally (Martin et al., 2011; Martin, Becker, Cicero, \& Kerns, 2013). Alternatively, both social anhedonia and introversion may be independently associated with alexithymia given that previous research has found that both are associated with difficulty identifying feelings and a decreased focus on feelings (Averill, 1999). Thus, if social anhedonia is distinct from introversion, we would expect it to be uniquely associated with measures of alexithymia above and beyond its relationship with introversion.

The current study addressed two questions. First, we tested whether social anhedonia and introversion are distinct using confirmatory factor analysis (CFA). If social anhedonia is distinct from introversion, we expected that the best fitting model was one in which social anhedonia scales loaded on one factor and introversion measures loaded on another. The second question the current study addressed was whether, if social anhedonia is distinct from introversion, social anhedonia was uniquely associated with aspects of alexithymia above and beyond any relationship with introversion. If social anhedonia was found to be distinct from introversion based on the results of the CFA, we expected social anhedonia to be associated with difficulty focusing on, identifying, and describing emotions after controlling for any association with introversion.

\section{METHODS}

\section{PARTICIPANTS}

The online battery was started 799 times. Of these, 29 instances were excluded because participants had started the battery more than once, as indicated by their entered name or student identification number. In these cases, we used only their first completed version of a scale in our analyses. In addition, participants were excluded if they did not provide informed consent indicated by entering their name $(n=11)$. We reasoned that this indicated they did not consent to having their data used in the study. Also, data from 3 participants were excluded because they completed less than half of the first questionnaire and did not restart the battery. We reasoned that this indicated study withdrawal. Finally, following previous research (e.g., Chmielewski, Fernandes, Yee, \& Miller, 1995), we excluded 92 participants because they endorsed three or more items on the Chapman Infrequency Scale (Chapman \& Chapman, 1983), 
which measures careless or invalid responses (e.g., "I cannot remember a time when I talked with someone who wore eyeglasses"). The final sample included in the analyses consisted of 664 participants (50.6\% male, $82.9 \%$ Caucasian, mean age $18.72, S D=1.04)$. All participants were native English speakers.

\section{MATERIALS}

Social Anhedonia (SA) Scales. Three measures of social anhedonia were included in the current study. The first measure was the Revised Social Anhedonia Scale (SA-SAS; Eckblad et al., 1982). Participants completed this 40-item, true/false questionnaire designed to measure lack of relationships and lack of pleasure from relationships (e.g., "Having close friends is not as important as many people say"). Higher scores indicate higher levels of social anhedonia (from current study, Cronbach's $\alpha=.85$ ). Means, standard deviations, and correlations for all scales can be found in Table 1 .

The second measure of social anhedonia was the Schizotypal Personality Questionnaire-No Close Friends subscale (SA-NCF; Raine, 1991). Using a yes/no response format, this 9-item subscale measures the extent to which individuals lack close friends (e.g., "I attach little importance to having close friends"). Higher scores indicate fewer close friends (from current study, Cronbach's $\alpha=.70$ ).

The third measure of social anhedonia was the Social Safeness and Pleasure Scale (SA-SSPS; Gilbert et al., 2009). Using a 5-point scale ranging from "almost all the time" to "almost never," participants were asked to rate the extent to which they agreed with 11 statements designed to assess experiences of pleasure and other positive feelings in social situations (e.g., "I feel a sense of warmth in my relationships with people"). Higher scores indicate less pleasure or positive feelings from social situations (from current study, Cronbach's $\alpha=.94)$. Previous research has found that scores on the SPSS are related to feelings of connectedness to others in both healthy individuals and individuals with mood disorders (Gilbert et al., 2009) as well as other real-world outcomes (e.g., received social support; Kelly, Zuroff, Leybman, \& Gilbert, 2012).

Introversion (I) Scales. Three measures of introversion were used in the current study. Taken from the International Personality Item Pool, the I-16 (Goldberg et al., 2006) was designed to measure introversion, specifically positive emotions and sociability, and was constructed to resemble a factor of Cattell's 16 Personality Factor Questionnaire (Cattell \& Mead, 2008). Individuals were asked to what extent 10 items characterize them (e.g." "Want to be left alone," "Enjoy spending time by myself"), and responses are made with a 5-point scale ranging from "very inaccurate" to "very accurate." Higher scores indicated higher levels of introversion (from current study, Cronbach's $\alpha=.81$ ).

The second measure of introversion, I-NEO (Goldberg et al., 2006), was also from the International Personality Item Pool. The I-NEO was based on the conceptualization of extraversion, including the facets of positive emotions and sociability, used in the NEO-Personality Inventory-Revised (Costa \& McCrae, 1992). Individuals were asked to what extent 20 items characterize 
TABLE 1. Pearson Correlation Coefficients, Reliabilities, Mean, and Standard Deviation for Social Anhedonia, Introversion, and Alexithymia Scales

\begin{tabular}{|c|c|c|c|c|c|c|c|c|c|c|c|c|c|c|c|c|}
\hline Scale & 1 & 2 & 3 & 4 & 5 & 6 & 7 & 8 & 9 & 10 & 11 & 12 & 13 & 14 & 15 & 16 \\
\hline \multicolumn{17}{|c|}{ Social Anhedonia Scales } \\
\hline 1. SA-SAS & - & & & & & & & & & & & & & & & \\
\hline 2. SA-NCF & $.65^{\mathrm{a}}$ & - & & & & & & & & & & & & & & \\
\hline 3. SA-SSPS & $.46^{\mathrm{a}}$ & $.54^{\mathrm{a}}$ & - & & & & & & & & & & & & & \\
\hline \multicolumn{17}{|c|}{ Introversion Scales } \\
\hline 4. $1-16$ & $.61^{\mathrm{a}}$ & $.48^{\mathrm{a}}$ & $.35^{\mathrm{a}}$ & - & & & & & & & & & & & & \\
\hline 5. I-NEO & $.57^{\mathrm{a}}$ & $.69^{\mathrm{a}}$ & $.54^{\mathrm{a}}$ & $.54^{\mathrm{a}}$ & - & & & & & & & & & & & \\
\hline 6. I-TBI & $.42^{\mathrm{a}}$ & $.50^{\mathrm{a}}$ & $.47^{\mathrm{a}}$ & $.42^{\mathrm{a}}$ & $.70^{\mathrm{a}}$ & - & & & & & & & & & & \\
\hline \multicolumn{17}{|c|}{ Alexithymia Measures: Decreased Focus on Feelings } \\
\hline 7. TAS-ExO & $.25^{\mathrm{a}}$ & $.19^{\mathrm{a}}$ & $.20^{\mathrm{a}}$ & .04 & $.17^{a}$ & $.14^{\mathrm{a}}$ & - & & & & & & & & & \\
\hline 8. TMMS-Att & $.38^{\mathrm{a}}$ & $.35^{\mathrm{a}}$ & $.31^{\mathrm{a}}$ & $.16^{\mathrm{a}}$ & $.32^{\mathrm{a}}$ & $.20^{\mathrm{a}}$ & $.45^{\mathrm{a}}$ & - & & & & & & & & \\
\hline 9. FAST-FolPos & $.31^{\mathrm{a}}$ & $.31^{\mathrm{a}}$ & $.43^{\mathrm{a}}$ & $.26^{\mathrm{a}}$ & $.41^{\mathrm{a}}$ & $.35^{\mathrm{a}}$ & $.17^{\mathrm{a}}$ & $.36^{\mathrm{a}}$ & - & & & & & & & \\
\hline 10. FAST-IgnPos & $.17^{a}$ & $.21^{\mathrm{a}}$ & $.22^{\mathrm{a}}$ & $.11^{\mathrm{b}}$ & $.22^{\mathrm{a}}$ & $.21^{\mathrm{a}}$ & $.22^{\mathrm{a}}$ & $.39^{\mathrm{a}}$ & $.39^{\mathrm{a}}$ & - & & & & & & \\
\hline 11. FAST-FolNeg & $-.29^{a}$ & $-.35^{\mathrm{a}}$ & $-.39^{a}$ & $-.26^{\mathrm{a}}$ & $-.35^{a}$ & $-.29^{a}$ & .02 & -.02 & $-.34^{\mathrm{a}}$ & $-.18^{a}$ & - & & & & & \\
\hline 12. FAST-IgnNeg & -.03 & -.003 & -.04 & $-.14^{\mathrm{a}}$ & -.05 & -.03 & $.19^{\mathrm{a}}$ & $.19^{\mathrm{a}}$ & $.01^{\mathrm{c}}$ & $.17^{\mathrm{a}}$ & $.22^{\mathrm{a}}$ & - & & & & \\
\hline \multicolumn{17}{|c|}{ Alexithymia Measures: Difficulty Identifying and Describing Feelings } \\
\hline 13. TAS-Id & $.26^{\mathrm{a}}$ & $.29^{\mathrm{a}}$ & $.32^{\mathrm{a}}$ & $.14^{\mathrm{a}}$ & $.25^{\mathrm{a}}$ & $.22^{\mathrm{a}}$ & $.22^{\mathrm{a}}$ & a $\quad .12^{\mathrm{b}}$ & $.16^{\mathrm{a}}$ & $.17^{\mathrm{a}}$ & $.29^{a}$ & .07 & - & & & \\
\hline 14. TAS-Des & $.38^{\mathrm{a}}$ & $.39^{\mathrm{a}}$ & $.34^{\mathrm{a}}$ & $.24^{\mathrm{a}}$ & $.35^{\mathrm{a}}$ & $.24^{\mathrm{a}}$ & $.22^{\mathrm{a}}$ & $.21^{\mathrm{a}}$ & $.16^{\mathrm{a}}$ & $.12^{\mathrm{b}}$ & $-.21^{\mathrm{a}}$ & .05 & $.53^{\mathrm{a}}$ & - & & \\
\hline 15. ECI-Prep & $.18^{\mathrm{a}}$ & $.16^{\mathrm{a}}$ & $.19^{a}$ & .03 & $.15^{\mathrm{a}}$ & .07 & $.54^{\mathrm{a}}$ & $.59^{\mathrm{a}}$ & $.29^{\mathrm{a}}$ & $.28^{\mathrm{a}}$ & $.08^{\mathrm{c}}$ & $.16^{\mathrm{a}}$ & .03 & $.11^{\mathrm{b}}$ & - & \\
\hline 16. ECl-Eff/Au & $.38^{\mathrm{a}}$ & $.41^{\mathrm{a}}$ & $.40^{\mathrm{a}}$ & $.28^{\mathrm{a}}$ & $.44^{\mathrm{a}}$ & $.33^{\mathrm{a}}$ & $.31^{\mathrm{a}}$ & $.55^{\mathrm{a}}$ & $.39^{a}$ & $.19^{a}$ & $-.19^{a}$ & .04 & $.16^{\mathrm{a}}$ & $.39^{a}$ & $.51^{\mathrm{a}}$ & - \\
\hline Mean & 8.5 & 1.8 & 23.8 & 28.9 & 46.4 & 37.6 & 18.03 & 29.80 & 13.89 & 9.58 & 17.27 & 25.41 & 12.61 & 11.10 & 16.23 & 24.07 \\
\hline$S D$ & 5.5 & 1.9 & 8.6 & 6.6 & 14.3 & 13.1 & 3.20 & 8.45 & 4.82 & 4.23 & 4.55 & 7.72 & 3.51 & 2.64 & 4.52 & 5.46 \\
\hline \multicolumn{17}{|c|}{$\begin{array}{l}\text { Note. SA-SAS = Social Anhedonia Scale; SA-NCF = Schizotypal Personality Questionnaire No Close Friends subscale; SA-SSPS = Social } \\
\text { Safeness and Pleasure Scale; I-16 = Introversion scale based on } 16 \text { Personality Factor Questionnaire from International Personality } \\
\text { Item Pool; I-NEO = Introversion scale based on the NEO from International Personality Item Pool; I-TBI = Transparent Bipolar } \\
\text { Inventory; TAS-ExO = Toronto Alexithymia Scale Externally-Oriented Thinking subscale; TMMS-Att = Trait Meta-Mood Scale Attention } \\
\text { to Feelings subscale; FAST-FolPos = Following Affective States Test Following Positive Emotions subscale; FAST-IgnPoS = Following } \\
\text { Affective States Ignoring Positive Emotions subscale; FAST-FolNeg = Following Affective States Test Following Negative Emotions } \\
\text { subscale; FAST-IgnNeg = Following Affective States Test Ignoring Negative Emotions subscale; TAS-Id = Toronto Alexithymia Scale } \\
\text { Difficulty Identifying Feelings subscale; TAS-Des = Toronto Alexithymia Scale Difficulty Describing Feelings subscale; ECI-Prep = } \\
\text { Emotional Creativity Inventory Preparedness subscale; ECI-Eff/Au = Emotional Creativity Inventory Effectiveness/Authenticity subscale. } \\
\text { ap } p<.001,{ }^{b} p<.01,{ }^{c} p<.05 \text {. }\end{array}$} \\
\hline
\end{tabular}

them (e.g., "I am skilled at handling social situations"). Responses were made with a 5-point scale, ranging from "very inaccurate" to "very accurate." Items were recoded so that higher scores indicated higher levels of introversion (from current study, Cronbach's $\alpha=.93$ ).

The third measure of introversion was the Transparent Bipolar Inventory (I-TBI; Goldberg, 1992). The I-TBI consisted of 10 bipolar adjective pairs (e.g., timid-bold; unsociable-sociable) designed to assess extraversion facets including positive emotions and sociability. Participants were asked to indicate how they would describe themselves using a 9-point scale. Items were recoded so that higher scores indicated higher levels of introversion (from current study, Cronbach's $\alpha=.88$ ). Factor analyses have consistently found the items from this scale load on an extraversion factor (Goldberg, 1992; Mackinnon, Jorm, 
Jacomb, Korten, \& Christensen, 1996). In addition, as a measure of extraversion, this scale has been used with a variety of populations from adolescents to older adults (Caruso \& Spirrison, 1994; Lance, Foster, Nemeth, Gentry, \& Drollinger, 2007; Schmitz, Kugler, \& Rollnik, 2003; Whitton \& Kuryluk, 2013).

Alexithymia Scales. Four scales that measured aspects of alexithymia were used in the current study. They included self-report measures of focusing on, identifying, and describing emotions. Items were coded so that higher scores indicated greater levels of alexithymia (i.e., decreased focus on feelings, greater difficulty identifying and describing emotions).

Measures of Decreased Focus on Feelings. In order to assess the extent to which individuals focus on feelings, three scales were used (six subscales total). First, participants completed the Externally-Oriented Thinking subscale from the Toronto Alexithymia Scale-20 (TAS; Bagby et al., 1994). This subscale consists of eight items (e.g., "I prefer talking to people about their daily activities rather than their feelings"). Responses were made with a 4-point scale, ranging from "never" to "always." Higher scores indicated decreased focus on feelings (from current study, Cronbach's $\alpha=.60$ ).

Also, participants completed the Attention to Feelings subscale from the Trait Meta-Mood Scale (TMMS; Salovey, Mayer, Goldman, Turvey, \& Palfai, 1995). This subscale consists of 13 items (e.g., "I don't pay much attention to my feelings"). Responses were made with a 5-point scale, ranging from "strongly disagree" to "strongly agree." Higher scores indicated decreased attention on feelings (from current study, Cronbach's $\alpha=.88$ ).

Last, participants completed the Following Affective States Test (FAST; Gasper \& Bramesfeld, 2006). This 21-item measure is comprised of four subscales: Following Positive Feelings, Ignore Positive Feelings, Following Negative Feelings, and Ignore Negative Feelings (e.g., Following Positive: "I often pay a lot of attention to my positive feelings"; Ignore Negative: "One should never be guided by negative emotions"). Responses were made with a 7-point scale, ranging from "strongly disagree" to "strongly agree." Items were recoded so that higher scores indicated decreased focus on feelings (i.e., higher scores on the Following subscales indicated lower attention to emotion and higher scores on the Ignore subscales indicated a greater desire to ignore emotions). In the current study, Cronbach's $\alpha$ ranged from .74 to .88 for these subscales. Previous reports of strong correlations with the TAS have provided convergent validity for the FAST as a measure of alexithymia (Gasper \& Bramesfeld, 2006).

Measures of Difficulty Identifying and Describing Feelings. In order to measure difficulties in identifying and describing feelings, two scales were used (four subscales total). First, both the Difficulty Identifying Feelings subscale (seven items; e.g., "I am often confused about what emotion I am feeling"; from current study, Cronbach's $\alpha=.82$ ) and the Difficulty Describing Feelings subscale (five items; e.g., "It is difficult for me to find the right words for my feelings"; from current study, Cronbach's $\alpha=.70$ ) from the TAS were used. Higher scores on these scales are associated with greater difficulty identifying and describing feelings. In both psychiatric and non-psychiatric popula- 
tions, social anhedonia has been positively associated with scores on the TAS (Berthoz, Lalanne, Crane, \& Hill, 2013; Gooding \& Tallent, 2003; Prince \& Berenbaum, 1993). In addition, introversion has been found to be positively associated with scores on the TAS (De Gucht, Fontaine, \& Fischler, 2004; Pandey \& Mandal, 1996; Timoney \& Holder, 2013).

In addition, both the Preparedness subscale (seven items; e.g., "I think about and try to understand my emotional reactions"; from current study, Cronbach's $\alpha=.74$ ) and the Effectiveness/Authenticity subscale (nine items; e.g., "I am good at expressing my emotions"; from current study, Cronbach's $\alpha=.73$ ) from the Emotional Creativity Inventory (ECI; Averill, 1999) were used. Responses were made with a 5-point scale, ranging from "definitely not true for myself" to "definitely true for myself." Items were recoded so that higher scores on these subscales are associated with greater difficulty identifying and describing feelings. The Preparedness subscale has been associated with the positive emotion facet of extraversion while scores on the Effectiveness/ Authenticity subscale have been associated with both the positive emotion and gregariousness facets of extraversion (Averill, 1999). In addition, both of these subscales from the ECI have been reported to be negatively associated with Difficulty Identifying Feelings and Difficulty Describing Feelings subscales of the TAS ( $r=-.24$ to -.64 ; Averill, 1999).

\section{PROCEDURE}

After informed consent was obtained, participants completed the social anhedonia, introversion, and alexithymia scales, as well as some other measures of emotion traits not reported here. Scale order was randomly determined, but we ensured that no two scales from one type were presented consecutively (i.e., two introversion scales were not presented consecutively). Each participant received the same order of scale presentation. All measures were completed online and were administered through Qualtrics.com, an Internet-based data collection provider. This research project was approved by the University's institutional review board, and all procedures were consistent with the principles of ethical conduct of human research.

\section{DATA ANALYSIS}

First, mean imputation (i.e., the participant's mean response from all items) was used if an individual item or items were missing from a scale (e.g., a participant did not respond to one item on a 10 -item scale). Percentage of imputations per scale ranged from $.16 \%$ to $.67 \%$ (median $=.20 \%$ )

Next, we transformed the data to account for differences in the measurement of social anhedonia and introversion. Social anhedonia is often measured as the sum of several dichotomous items (e.g., SA-SAS and SA-NCF), each of which is usually endorsed at a low rate (e.g., Martin et al., 2011, 2012). In contrast, introversion is usually measured using a Likert scale. This raises two related potential problems. First, the low-rate dichotomous items on the SA-SAS and SA-NCF social anhedonia scales may only capture variance at the very low end of the extraversion distribution. If so, perhaps social anhedonia 
is equivalent to high introversion but will appear distinct from introversion if the latter is measured with normally distributed Likert data, which capture variance across the distribution of the introversion-extraversion spectrum. To rule out this possibility, we dichotomized and summed the items from the other social anhedonia scale (SA-SSPS) and all three introversion scales that were given in Likert format. The point at which we cut each scale was selected so that the item mean was as close as possible to the mean endorsement rate for the two dichotomously scored social anhedonia scales (approximately .2). Second, the distributions of the SA-SAS and SA-NCF social anhedonia scales are non-normal and positively skewed, which may cause these scales to correlate differently with each other than with introversion scales. To rule out this possibility, we took the logarithm of the total score on all scales to ensure the scales were approximately normally distributed.

Data were analyzed using confirmatory factor analysis (CFA) in MPlus 7.1 (Muthén \& Muthén, 2012). CFA allows for the assessment of fit between observed data (i.e., data collected from participants) and a theorized, higher order latent variable structure (Mueller \& Hancock, 2001). First, a two-factor model was estimated, with the three social anhedonia scales (SA-SAS, SA-NCF, and SA-SSPS) loading on one factor, Social Anhedonia, and the three introversion scales (I-NEO, I-16, and I-TBI) loading on a second factor, Introversion. Then, the model was re-estimated with the constraint that the correlation between Social Anhedonia and Introversion was equal to 1, equivalent to a single-factor model. These models, the two-factor model without a constraint and the two-factor model with the constraint, were compared using a chisquare difference test in order to test the hypothesis that social anhedonia and introversion are the same construct. As mentioned in the Materials section, the three Social Anhedonia scales were administered so that affirmative answers (i.e., answering "yes" or "true") indicated higher social anhedonia. Additionally, the I-16 is administered such that affirmative answers (i.e., choosing higher scores on a Likert scale of accuracy of the statements) indicated higher introversion. Thus, we correlated errors of the I-16 and the three social anhedonia scales to account for this method variance.

Finally, in order to provide additional support that social anhedonia is not just introversion, we tested whether social anhedonia was associated with aspects of alexithymia above and beyond introversion by simultaneously entering the Social Anhedonia and Introversion factors as predictors of alexithymia measures.

\section{RESULTS}

\section{MODEL COMPARISONS}

As can be seen in Table 2, the two-factor model (Model 1) with the three social anhedonia scales (SA-SAS, SA-NCF, and SA-SSPS) loading on a Social Anhedonia factor and the three introversion scales (I-NEO, I-16, and I-TBI) loading on an Introversion factor (Model 1) fit the data well. In this model, the estimated correlation between Social Anhedonia and Introversion was $r=.81, p<.001$. This unconstrained model fit the data better than Model 
TABLE 2. Model Fit Comparison

\begin{tabular}{lccccccc}
\hline Model & RMSEA & CFI & SRMR & AIC & BIC & $\chi^{2}$ & $d f$ \\
\hline Model 1 & $<0.001$ & 1.00 & 0.01 & -4989.23 & -4890.27 & 4.97 & 5 \\
Model 2: Constrained & 0.11 & 0.96 & 0.03 & -4927.84 & -4833.38 & 54.36 & 6 \\
\hline
\end{tabular}

Note. Model 1: Two-factor model with the three social anhedonia manifest variables loading on a social anhedonia factor and the three introversion variables loading on an introversion factor. Model 2: Two-factor model in which the correlation between the social anhedonia and introversion factor is constrained to equal 1 . RMSEA = root mean square of approximation; $\mathrm{CFI}=$ comparative fix index; $\mathrm{SRMR}=$ standardized root mean square residual; $\mathrm{AIC}=\mathrm{Akaike}$ information criterion; $\mathrm{BIC}=$ Bayesian information criterion.

2, in which the correlation between the Social Anhedonia and Introversion factors was constrained to be 1 (Satorra-Bentler $\chi^{2}$ difference (1) 43.50, $p<$ $.001)$. This finding suggests that social anhedonia and introversion are distinct but related constructs.

\section{RELATIONS WITH ALEXITHYMIA}

If social anhedonia is simply high introversion, then we would expect to find that introversion could account for the relations between social anhedonia and alexithymia that have been found in previous research. However, if social anhedonia is distinct from introversion, we would expect to find that social anhedonia is still significantly associated with alexithymia when measures of alexithymia are simultaneously regressed on the Social Anhedonia and Introversion factors. To test this, we simultaneously entered the Social Anhedonia and Introversion factors as specified in Model 1 as predictors of alexithymia measures. These results can be interpreted like standardized beta weights in a multiple regression analysis.

Relations With Measures of Decreased Focus on Feelings. We expected to find that social anhedonia would be positively associated with alexithymia evidenced by a decreased focus on feelings even after removing variance shared with introversion. As can be seen in Table 3, the social anhedonia factor was positively associated with a decreased focus on feelings in general (indicated by positive associations with both the TAS-Externally-Oriented Thinking subscale and the TMMS-Attention to Feelings subscale) while introversion was negatively associated with a decreased focus on feelings in general (indicated by negative associations with both the TAS-ExternallyOriented Thinking subscale and the TMMS-Attention to Feelings subscale). However, both the negative relation between Introversion and these subscales may be a result of the removal of variance shared with social anhedonia. This is because the zero-order correlations between Introversion and the TAS subscale were non-significant or weakly positive (mean $r=.14$ ), and the zero-order correlations between Introversion and the TMMS were weakly positive (mean $r=.23$ ).

By asking questions about focusing on positive and negative feelings separately, the FAST subscales allow for a more fine-grained analysis of decreased focusing on feelings. As can be seen in Table 3, results show that people with 
TABLE 3. Standardized Coefficients of Alexithymia Measures Regressed on the Social Anhedonia and Introversion Factors

\begin{tabular}{|c|c|c|}
\hline & Social Anhedonia & Introversion \\
\hline \multicolumn{3}{|l|}{ Decreased Focus on Feelings } \\
\hline Externally-oriented thinking & $.50 * * *$ & $-.30 * *$ \\
\hline Decreased attention to feelings & $.66^{* * *}$ & $-.26^{* *}$ \\
\hline Decreased focus on positive feelings & $.31^{* *}$ & .11 \\
\hline Ignore positive feelings & $.33^{* * *}$ & -.11 \\
\hline Decreased focus on negative feelings & $-.36^{* * *}$ & -.08 \\
\hline Ignore negative feelings & $-.25^{* *}$ & $.21^{*}$ \\
\hline \multicolumn{3}{|l|}{ Difficulty Identifying and Describing Feelings } \\
\hline Difficulty identifying emotions (TAS) & $.53^{* * *}$ & $-.23 *$ \\
\hline Difficulty describing emotions (TAS) & $.57^{* * *}$ & -.14 \\
\hline Difficulty identifying emotions (Prep) & $.46^{* *}$ & $-.30^{* *}$ \\
\hline Difficulty describing emotions (Eff/Au) & $.47^{* * *}$ & .05 \\
\hline \multicolumn{3}{|c|}{$\begin{array}{l}\text { Note. These results can be interpreted like standardized beta weights in a multiple regression analysis. Externally- } \\
\text { oriented thinking = Toronto Alexithymia Scale Externally-Oriented Thinking subscale; Decreased attention to } \\
\text { feelings = Trait Meta-Mood Scale Attention to Feelings subscale; Decreased focus on positive feelings = Following } \\
\text { Affective States Test Following Positive Emotions subscale; Ignore positive feelings = Following Affective States } \\
\text { Ignoring Positive Emotions subscale; Decreased focus on negative feelings = Following Affective States Test Following } \\
\text { Negative Emotions subscale; Ignore negative feelings = Following Affective States Test Ignoring Negative Emotions } \\
\text { subscale; Difficulty identifying emotions (TAS) = Toronto Alexithymia Scale Difficulty Identifying Feelings subscale; } \\
\text { Difficulty describing emotions (TAS) = Toronto Alexithymia Scale Difficulty Describing Feelings subscale; Difficulty } \\
\text { identifying emotions (Prep) = Emotional Creativity Inventory Preparedness subscale; Difficulty describing emotions } \\
\text { (Eff/Au) = Emotional Creativity Inventory Effectiveness/Authenticity subscale. }{ }^{*} p<.05 .{ }^{* *} p<.01 .{ }^{* * *} p<.001 .\end{array}$} \\
\hline
\end{tabular}

social anhedonia have a decreased focus on positive emotions and a greater desire to ignore their positive emotions (indicated by positive associations between Social Anhedonia and the Follow Positive Feelings subscale and Social Anhedonia and the Ignore Positive Feelings subscale). At the same time, people with social anhedonia have an increased focus on negative emotions and have a decreased desire to ignore their negative emotions (indicated by negative associations between Social Anhedonia and the Follow Negative Feelings subscale and Social Anhedonia and the Ignore Negative Feelings subscale). As predicted, these results are statistically significant, even when removing variance shared with introversion. Introversion was positively associated with ignoring negative feelings but was not significantly associated with the other FAST subscales.

Relations With Measures of Difficulty Identifying and Describing Feelings. We expected to find that Social Anhedonia would be associated with difficulty identifying and describing feelings even after removing variance shared with Introversion. Consistent with this, as can be seen in Table 3, Social Anhedonia was positively associated with all measures of difficulty identifying and describing feelings (i.e., the TAS-Difficulty Identifying Feelings, TAS-Difficulty Describing Feelings, ECI-Effectiveness/Authenticity, and ECI-Preparedness subscales). In contrast, Introversion was negatively associated with both 
the TAS-Difficulty Identifying Feelings subscale and the ECI-Preparedness subscale. Similar to the focusing on feelings results, the negative association between Introversion and the TAS-Difficulty Identifying Feelings subscale and Introversion and the ECI-Preparedness subscale may be a result of removing shared variance with Social Anhedonia because the zero-order correlations between Introversion and this TAS subscale were weakly positive (mean $r=.20$ ) and the zero-order correlations between Introversion and this ECI subscale were non-significant or weakly positive (mean $r=.08$ ). Taken together, these results suggest that in addition to having a decreased focus on positive feelings, people with social anhedonia may experience difficulty with identifying and describing feelings, even when removing variance shared with introversion.

\section{DISCUSSION}

Despite a general consideration of social anhedonia as a distinct construct from introversion in the literature, recent evidence suggested that given the amount of overlap between the two, this might not be a completely accurate reflection of the true state of nature (Cicero \& Kerns, 2010; Martin et al., 2012). To clarify the nature of social anhedonia empirically, the current study investigated the relationship between social anhedonia and introversion using confirmatory factor analysis. Even if they loaded on a separate factor, it is possible that social anhedonia scales measure extreme introversion because they are measured in different ways: social anhedonia scales contain many dichotomous items that have a low rate of endorsement in the general population, while introversion is measured with responses to items on Likert scales. Therefore, it was important to rule out the possibility that social anhedonia scales simply measure a more extreme manifestation of introversion. To account for this possibility, we rescored the introversion measures in a way that resembled social anhedonia measures: as a series of dichotomous items with low rates of endorsement. If social anhedonia were simply extreme introversion, then a model with a single factor should adequately explain the variance in measures of introversion and social anhedonia when they were scored in this way. However, the single factor solution fit the data worse than the two-factor solution. This is inconsistent with the hypothesis that social anhedonia is simply a more extreme form of introversion. Rather, the current findings are consistent with the hypothesis that these are distinct but related constructs. This provides empirical support of the continued treatment of social anhedonia as a separate construct in the literature. At the same time, the extent of overlap between social anhedonia and introversion suggests the relevance of a large literature on the introversion-extraversion continuum to our understanding of social anhedonia.

The finding that social anhedonia is distinct from but related to introversion enhances our understanding of the nature of social anhedonia. Because social anhedonia predicts the onset of SZ-spectrum personality disorders above and beyond any subthreshold psychotic symptoms (e.g., illusions, odd 
beliefs; Brown et al., 2007; Gooding et al., 2005; Kwapil, 1998), investigators have become increasingly interested in this phenomenon in predicting onset (e.g., Kwapil, Gross, Silvia, \& Barrantes-Vidal, 2013; Tarbox et al., 2013). An increased focus on unique associations of dysfunction in social anhedonia could increase prediction accuracy of SZ-spectrum disorders over the current measures. For example, for the Structured Interview for Prodromal Syndromes (Miller et al., 2003), a measure used to identify those at risk for the development of SZ-spectrum disorders, summary scores are obtained for a number of areas including "social anhedonia" (number of friends, preference to be alone, and passive social participation) and "expression of emotion" (diminished emotional response, lack of spontaneity of conversation). Taken out of context, these descriptors could be mistaken as indicators of introversion. Thus, a refinement of the social anhedonia construct by highlighting unique areas of dysfunction may increase our ability to identify individuals at risk. One area of unique dysfunction is alexithymia.

In the current study, we found that social anhedonia predicted measures of alexithymia above and beyond any relationship with introversion. This suggests not only that social anhedonia is distinct from introversion, but also that this distinction is theoretically meaningful and is an additional step toward a better understanding of the nature of social anhedonia. The recent suggestion that anhedonia may be an "emotion paradox" (Strauss \& Gold, 2012) has posed challenges for those who study this phenomenon. This paradox describes the discrepant results found in anhedonia related to reports of positive emotions. Specifically, anhedonia is associated with: a) decreased positive emotion in response to laboratory stimuli and in everyday life (e.g., Blanchard et al., 1994; Brown et al., 2007; Fitzgibbons \& Simons, 1992); but b) some reports of no differences in experiences of "in-the-moment" pleasure in SZ-spectrum disorders (for reviews, see Cohen \& Minor, 2010; Kring \& Moran, 2008). The current findings suggest that alexithymia could be critical in conceptualizing and understanding social anhedonia. That is, these findings suggest anhedonia is not only associated with decreased trait positive emotion also evident in introversion but, more specifically, is associated with alexithymia. Thus, a more detailed examination of a focus on and identification and description of feelings could help to explain the emotion paradox. For example, if one does not focus on positive feelings associated with a stimulus in the moment, he or she may be less likely to encode that information into memory. Subsequently, it may be impossible to recall these positive feelings when asked about them at a later time. Thus, reports of anhedonia may arise.

While enhancing our understanding of social anhedonia, the results of the current study shed light on a factor that could help discriminate between personality disorders characterized by high introversion. In a meta-analytic review, Saulsman and Page (2004) report that schizoid, schizotypal, avoidant, and, to a lesser extent, dependent, personality disorders are characterized by high introversion. If levels of social anhedonia are taken into account when assessing personality, differentiation between these personality disorders may be clearer. This delineation between personality disorders characterized by social 
anhedonia (e.g., schizoid, schizotypal) versus high introversion (e.g., avoidant, dependent) could lead to a more specific treatment target. For example, interventions aimed at ameliorating alexithymia may lead to better outcomes for schizoid and schizotypal personality disorder over others.

The current findings are consistent with previous work that has focused on the relationship between social anhedonia or introversion and levels of functioning. For example, people with social anhedonia have poorer functioning in a variety of contexts, including social, community, and occupational settings (e.g., Blanchard et al., 1994, 1998), compared to individuals without social anhedonia. In contrast, people with a high level of introversion do not have the same poor functioning in a number of the same contexts and, in fact, may have better functioning in some types of occupations than individuals with a high level of extraversion (e.g., Lysaker, Bell, Kaplan, \& Bryson, 1998). To our knowledge though, the effect of social anhedonia and introversion on social functioning has not been reported in a single study using the same measure. A future study could utilize a behavioral, laboratorybased measure of social functioning (e.g., Conversation Probe role-play test; Penn, Hope, Spaulding, \& Kucera, 1994) to see how differences between these 2 constructs manifest.

The current findings are also consistent with previous evidence that both social anhedonia (e.g., Meyer \& Lenzenweger, 2009; Rey, Jouvent, \& Dubal, 2009) and introversion (e.g., Bienvenu, Hettema, Neale, Prescott, \& Kendler, 2007; Stemberger, Turner, Beidel, \& Calhoun, 1995) are distinct from but related to social anxiety (Brown et al., 2007; Cicero, Kreig, Becker, \& Kerns, 2014). For example, using a similar methodology as employed here, Cicero and colleagues (2014) found that social anhedonia measures and social anxiety measures load on separate factors. To our knowledge though, the relationship between these 3 constructs has not been examined in a single study. Further research could investigate whether social anxiety mediates or moderates the relation between social anhedonia and introversion.

Although it is not uncommon to consider measures of social anhedonia on a continuous scale as was done in the current work (e.g., Kerns et al., 2008; Kwapil, Barrantes-Vidal, \& Silvia, 2008; Martin et al., 2011), many studies using the Revised Social Anhedonia scale in non-clinical populations create groups of individuals with extreme scores who may be at greater risk for the development of schizophrenia-spectrum disorders (e.g., Kerns, Docherty, \& Martin, 2008; Martin, Cicero, \& Kerns, 2011; Martin \& Kerns, 2010). Future research could examine the relationship between social anhedonia and introversion in such a population to investigate whether the strength of the relationship changes.

Future research is also needed to examine whether anticipatory ("pleasure related to future activities"; Gard et al., 2007, p. 254) and consummatory ("pleasure when directly engaged in an activity"; Gard et al., 2007, p. 254) deficits are unique to social anhedonia and are not associated with introversion. Although anhedonia has been associated with deficits in one or both of these types of pleasure (Gard, Germans Gard, Kring, \& John, 2006; Martin et al., 2011), these same deficits may not observed in introversion and to our knowledge, have not been previously investigated. 


\section{REFERENCES}

American Psychiatric Association. (2013). Diagnostic and statistical manual of mental disorders (5th ed.). Washington, DC: Author.

Andreasen, N. C., \& Flaum, M. A. (1982). Schizophrenia: The characteristic symptoms. Schizophrenia Bulletin, 17, 27-49.

Averill, J. R. (1999). Individual differences in emotional creativity: Structure and correlates. Journal of Personality, 67(2), 331-371.

Bagby, R. M., Bindseil, K. D., Schuller, D. R., Rector, N. A., Young, L. T., Cooke, R. G., . . . Joffe, R. T. (1997). Relationship between the five-factor model of personality and unipolar, bipolar and schizophrenic patients. Psychiatry Research, 70(2), 83-94.

Bagby, R. M., Parker, J. D., \& Taylor, G. J. (1994). The twenty-item Toronto Alexithymia ScaleI. Item selection and cross-validation of the factor structure. Journal of Psychosomatic Research, 38(1), 23-32.

Berenbaum, H., \& Fujita, F. (1994). Schizophrenia and personality: Exploring the boundaries and connections between vulnerability and outcome. Journal of Abnormal Psychology, 103(1), 148-158.

Berthoz, S., Lalanne, C., Crane, L., \& Hill, E. L. (2013). Investigating emotional impairments in adults with autism spectrum disorders and the broader autism phenotype. Psychiatry Research, 208(3), 257-264. doi:10.1016/j. psychres.2013.05.014

Bienvenu, O. J., Hettema, J. M., Neale, M. C., Prescott, C. A., \& Kendler, K. S. (2007). Low extraversion and high neuroticism as indices of genetic and environmental risk for social phobia, agoraphobia, and animal phobia. American Journal of Psychiatry, 164(11), 1714-1721. doi:10.1176/appi. ajp.2007.06101667

Blanchard, J. J., Bellack, A. S., \& Mueser, K. T. (1994). Affective and social-behavioral correlates of physical and social anhedonia in schizophrenia. Journal of Abnormal Psychology, 103(4), 719-728.

Blanchard, J. J., Mueser, K. T., \& Bellack, A. S. (1998). Anhedonia, positive and negative affect, and social functioning in schizophrenia. Schizophrenia Bulletin, 24(3), 413-424.

Brown, L. H., Silvia, P. J., Myin-Germeys, I., \& Kwapil, T. R. (2007). When the need to belong goes wrong: The expression of social anhedonia and social anxiety in daily life. Psychological Science, 18(9), 778-782. doi:10.1111/j.1467-9280.2007.01978.x

Caruso, J. C., \& Spirrison, C. L. (1994). Early memories, normal personality variation, and coping. Journal of Personality Assessment, 63, 517-533.

Cattell, H. E. P., \& Mead, A. D. (2008). The 16PF Questionnaire. In G. J. Boyle, G. Matthews,
\& D. H. Saklofske (Eds.), The Sage handbook of personality theory and testing: Vol. 2, Personality measurement and testing. Los Angeles, CA: Sage.

Chapman, J. P., \& Chapman, L. J. (1983). Reliability and the discrimination of normal and pathological groups. Journal of Nervous and Mental Disease, 171(11), 658-661.

Chmielewski, P. M., Fernandes, L. O., Yee, C. M., \& Miller, G. A. (1995). Ethnicity and gender in scales of psychosis proneness and mood disorders. Journal of Abnormal Psychology, 104(3), 464-470.

Cicero, D. C., \& Kerns, J. G. (2010). Multidimensional factor structure of positive schizotypy. Journal of Personality Disorders, 24(3), 327 343. doi:10.1521/pedi.2010.24.3.327

Cicero, D. C., Kreig, A., Becker, T. M., \& Kerns, J. G. (2104). Evidence for the discriminant validity of the Revised Social Anhedonia Scale from social anxiety. Manuscript submitted for publication.

Cohen, A. S., \& Minor, K. S. (2010). Emotional experience in patients with schizophrenia revisited: Meta-analysis of laboratory studies. Schizophrenia Bulletin, 36(1), 143-150. doi:10.1093/schbul/sbn061

Cohen, A. S., Najolia, G. M., Brown, L. A., \& Minor, K. S. (2011). The state-trait disjunction of anhedonia in schizophrenia: Potential affective, cognitive and social-based mechanisms. Clinical Psychology Review, 31(3), 440-448. doi:10.1016/j.cpr.2010.11.001

Costa, P. T., \& McCrae, R. R. (1990). Personality disorders and the five-factor model of personality. Journal of Personality Disorders, 4 , 362-371.

Costa, P. T., \& McCrae, R. R. (1992). NEO PI-R professional manual. Odessa, FL: Psychological Assessment Resources.

De Gucht, V., Fontaine, J., \& Fischler, B. (2004). Temporal stability and differential relationships with neuroticism and extraversion of the three subscales of the 20-item Toronto Alexithymia Scale in clinical and nonclinical samples. Journal of Psychosomatic Research, 57(1), 25-33. doi:10.1016 S0022-3999(03)00577-4

Depue, R. A., \& Collins, P. F. (1999). Neurobiology of the structure of personality: Dopamine, facilitation of incentive motivation, and extraversion. Behavioral and Brain Sciences, 22(3), 491-517; discussion 518-469.

Eckblad, M., Chapman, L. J., Chapman, J. P., \& Mishlove, M. (1982). The Revised Social Anhedonia Scale. Department of Psychology, University of Wisconsin

Fenton, W. S., \& McGlashan, T. H. (1991). Natural history of schizophrenia subtypes. II. Positive and negative symptoms and long-term 
course. Archives of Genernal Psychiatry, 48(11), 978-986.

Fitzgibbons, L., \& Simons, R. F. (1992). Affective response to color-slide stimuli in subjects with physical anhedonia: A three-systems analysis. Psychophysiology, 29(6), 613-620.

Gard, D. E., Germans Gard, M., Kring, A. M., \& John, O. (2006). Anticipatory and consummatory components of the experience of pleasure: A scale development study. Journal of Research in Personality, 40, 1086-1102.

Gard, D. E., Kring, A. M., Gard, M. G., Horan, W. P., \& Green, M. F. (2007). Anhedonia in schizophrenia: Distinctions between anticipatory and consummatory pleasure. Schizophrenia Research, 93(1-3), 253-260. doi:10.1016/j. schres.2007.03.008

Gasper, K., \& Bramesfeld, K. D. (2006). Should I follow my feelings? How individual differences in following feelings influence affective wellbeing, experience, and responsiveness. Journal in Research in Personality, 40, 986-1014.

Gilbert, P., McEwan, K., Mitra, R., Richter, A., Franks, L., Mills, A., . . Gale, C. (2009). An exploration of different types of positive affect in students and patients with a bipolar disorder. Clinical Neuropsychiatry, 6, 135-143.

Goldberg, L. R. (1992). The development of markers for the Big-Five factor structure. Psychological Assessment, 4, 26-42.

Goldberg, L. R. (1993). The structure of phenotypic personality traits. American Psychologist, 48(1), 26-34.

Goldberg, L. R., Johnson, J. A., Eber, H. W., Hogan, R., Ashton, M. C., Cloninger, C. R., \& Gough, H. C. (2006). The International Personality Item Pool and the future of publicdomain personality measures. Journal of Research in Personality, 40, 84-96.

Gooding, D. C., Davidson, R. J., Putnam, K. M., \& Tallent, K. A. (2002). Normative emotionmodulated startle response in individuals at risk for schizophrenia-spectrum disorders. Schizophrenia Research, 57(1), 109-120.

Gooding, D. C., \& Tallent, K. A. (2003). Spatial, object, and affective working memory in social anhedonia: An exploratory study. Schizophrenia Research, 63(3), 247-260.

Gooding, D. C., Tallent, K. A., \& Matts, C. W. (2005). Clinical status of at-risk individuals 5 years later: Further validation of the psychometric high-risk strategy. Journal of Abnormal Psychology, 114(1), 170-175. doi:10.1037/0021-843X.114.1.170

Grant, P. M., Huh, G. A., Perivoliotis, D., Stolar, N. M., \& Beck, A. T. (2012). Randomized trial to evaluate the efficacy of cognitive therapy for low-functioning patients with schizophrenia. Archives of General Psychiatry, 69(2), 121-127. doi:10.1001/ archgenpsychiatry.2011.129
Green, M. F., Hellemann, G., Horan, W. P., Lee, J., \& Wynn, J. K. (2012). From perception to functional outcome in schizophrenia: Modeling the role of ability and motivation. Archives of General Psychiatry, 69(12), 1216-1224. doi:10.1001/ archgenpsychiatry.2012.652

Gurrera, R. J., Nestor, P. G., \& O’Donnell, B. F. (2000). Personality traits in schizophrenia: Comparison with a community sample. Journal of Nervous and Mental Disease, 188(1), 31-35.

Häfner, H., Maurer, K., Löffler, W., an der Heiden, W., Hambrecht, M., \& Schultze-Lutter, F. (2003). Modeling the early course of schizophrenia. Schizophrenia Bulletin, 29(2), 325-340.

Hills, P., \& Argyle, M. (2001). Happiness, introversion-extraversion, and happy introverts. Personality and Individual Differences, 30, 595-608.

Horan, W. P., Green, M. F., Kring, A. M., \& Nuechterlein, K. H. (2006). Does anhedonia in schizophrenia reflect faulty memory for subjectively experienced emotions? Journal of Abnormal Psychology, 115(3), 496-508. doi:10.1037/0021-843X.115.3.496

Kelly, A. C., Zuroff, D. C., Leybman, M. J., \& Gilbert, P. (2012). Social safeness, received social support, and maladjustment: Testing a tripartite model of affect regulation. Cognitive Therapy and Research, 36, 815-826.

Kentros, M., Smith, T. E., Hull, J., McKee, M., Terkelsen, K., \& Capalbo, C. (1997). Stability of personality traits in schizophrenia and schizoaffective disorder: A pilot project. Journal of Nervous and Mental Disease, 185(9), 549-555.

Kerns, J. G. (2006). Schizotypy facets, cognitive control, and emotion. Journal of Abnormal Psychology, 115(3), 418-427. doi:10.1037/0021-843X.115.3.418

Kerns, J. G., Docherty, A. R., \& Martin, E. A. (2008). Social and physical anhedonia and valence and arousal aspects of emotional experience. Journal of Abnormal Psychology, 117(4), 735-746. doi:10.1037/a0013601

Kring, A. M., Gur, R. E., Blanchard, J. J., Horan, W. P., \& Reise, S. P. (2013). The Clinical Assessment Interview for Negative Symptoms (CAINS): Final development and validation. American Journal of Psychiatry, 170(2), 165172. doi:10.1176/appi.ajp.2012.12010109

Kring, A. M., \& Moran, E. K. (2008). Emotional response deficits in schizophrenia: Insights from affective science. Schizophrenia Bulletin, 34(5), 819-834. doi:10.1093/schbul/ sbn071

Kwapil, T. R. (1998). Social anhedonia as a predictor of the development of schizophreniaspectrum disorders. Journal of Abnormal Psychology, 107(4), 558-565. 
Kwapil, T. R., Barrantes-Vidal, N., \& Silvia, P. J. (2008). The dimensional structure of the Wisconsin Schizotypy Scales: Factor identification and construct validity. Schizophrenia Bulletin, 34(3), 444-457. doi:10.1093/schbul/sbm098

Kwapil, T. R., Gross, G. M., Silvia, P. J., \& Barrantes-Vidal, N. (2013). Prediction of psychopathology and functional impairment by positive and negative schizotypy in the Chapmans' ten-year longitudinal study. Journal of Abnormal Psychology, 122(3), 807-815. doi:10.1037/a0033759

Kwapil, T. R., Silvia, P. J., Myin-Germeys, I., Anderson, A. J., Coates, S. A., \& Brown, L. H. (2009). The social world of the socially anhedonic: Exploring the daily ecology of asociality. Journal of Research in Personality, 43, 103-106.

Lance, C. E., Foster, M. R., Nemeth, Y. M., Gentry, W. A., \& Drollinger, S. (2007). Extending the nomological network of assessment center construct validity: Prediction of crosssituationally consistent and specific aspects of assessment center performance. Human Performance, 20, 345-362.

Lenzenweger, M. F. (1999). Schizophrenia: Refining the phenotype, resolving endophenotypes. Behaviour Research and Therapy, 37(3), 281-295.

Lewandowski, K. E., Barrantes-Vidal, N., NelsonGray, R. O., Clancy, C., Kepley, H. O., \& Kwapil, T. R. (2006). Anxiety and depression symptoms in psychometrically identified schizotypy. Schizophrenia Research, 83(2-3), 225-235. doi:10.1016/j.schres.2005.11.024

Lucas, R. E., Diener, E., Grob, A., Suh, E. M., \& Shao, L. (2000). Cross-cultural evidence for the fundamental features of extraversion. Journal of Personlity and Social Psychology, 79(3), 452-468.

Lysaker, P. H., Bell, M. D., Kaplan, E., \& Bryson, G. (1998). Personality and psychosocial dysfunction in schizophrenia: The association of extraversion and neuroticism to deficits in work performance. Psychiatry Research, 80(1), 61-68.

Mackinnon, A., Jorm, A. F., Jacomb, P. A., Korten, A. E., \& Christensen, H. (1996). Use of the Transparent Bipolar Inventory to measure the big-five personality factors in an epidemiological survey of the elderly. Personality and Individual Differences, 21, 1051-1054.

Martin, E. A., Bailey, D. H., Cicero, D. C., \& Kerns, J. G. (2012). Social networking profile correlates of schizotypy. Psychiatry Research, 200(2-3), 641-646. doi:10.1016/j. psychres.2012.06.031

Martin, E. A., Becker, T. M., Cicero, D. C., Docherty, A. R., \& Kerns, J. G. (2011). Differential associations between schizotypy facets and emotion traits. Psychiatry Research, 187(1-2), 94-99. doi:10.1016/j. psychres.2010.12.028
Martin, E. A., Becker, T. M., Cicero, D. C., \& Kerns, J. G. (2013). Examination of affective and cognitive interference in schizophrenia and relation to symptoms. Journal of Abnormal Psychology, 122(3), 733-744. doi:10.1037/ a0033956

Martin, E. A., Cicero, D. C., \& Kerns, J. G. (2011). Social anhedonia, but not positive schizotypy, is associated with poor affective control. Personality Disorders: Theory, Research, and Treatment, 3, 263-272.

Martin, E. A., \& Kerns, J. G. (2010). Social anhedonia associated with poor evaluative processing but not with poor cognitive control. Psychiatry Research, 178, 416-424.

Mason, O. (1995). A confirmatory factor analysis of the structure of schizotypy. European Journal of Personality, 9, 271-281.

Meehl, P. E. (1962). Schizotaxia, schizotypy, schizophrenia. American Psychologist, 17, 827-838.

Meyer, E. C., \& Lenzenweger, M. F. (2009). The specificity of referential thinking: A comparison of schizotypy and social anxiety. Psychiatry Research, 165(1-2), 78-87. doi:10.1016/j. psychres.2007.10.015

Miller, T. J., McGlashan, T. H., Rosen, J. L., Cadenhead, K., Cannon, T., Ventura, J., ... Woods, S. W. (2003). Prodromal assessment with the structured interview for prodromal syndromes and the scale of prodromal symptoms: predictive validity, interrater reliability, and training to reliability. Schizophrenia Bulletin, 29(4), 703-715.

Mueller, R. O., \& Hancock, G. R. (2001). Factor analysis and latent structure: Confirmatory factor analysis. In N. J. Smelser \& P. B. Baltes (Eds.), International encyclopedia of the social and behavioral sciences (pp. 5239-5244). Oxford, England: Pergamon.

Muthén, L. K., \& Muthén, B. O. (2012). MPlus 7.1. Los Angeles, CA: Muthén \& Muthén.

Pandey, R., \& Mandal, M. K. (1996). Eysenckian personality dimensions and alexithymia: Examining the overlap in terms of perceived autonomic arousal. Personality and Individual Differences, 4, 499-504.

Pavot, W., Diener, E., \& Fujita, F. (1990). Extraversion and happiness. Personality and Individual Differences, 11, 1299-1306.

Penn, D. L., Hope, D. A., Spaulding, W., \& Kucera, J. (1994). Social anxiety in schizophrenia. Schizophrenia Research, 11, 277-284.

Prince, J., \& Berenbaum, H. (1993). Alexithymia and hedonic capacity. Journal of Research in Personality, 27, 15-22.

Rado, S. (1960). Theory and therapy: The theory of schizotypal organization and its application to the treatment of decompensated schizotypal behavior. In S. C. Scher \& H. R. Davis (Eds.), The outpatient treatment of 
schizophrenia (pp. 87-101). New York, NY: Grune \& Stratton.

Raine, A. (1991). The SPQ: A scale for the assessment of schizotypal personality based on DSM-III-R criteria. Schizophrenia Bulletin, 17(4), 555-564.

Rey, G., Jouvent, R., \& Dubal, S. (2009). Schizotypy, depression, and anxiety in physical and social anhedonia. Journal of Clinical Psychology, 65(7), 695-708. doi:10.1002/ jclp. 20577

Ross, S. R., Lutz, C. J., \& Bailley, S. E. (2002). Positive and negative symptoms of schizotypy and the five-factor model: A domain and facet level analysis. Journal of Personality Assessment, 79(1), 53-72. doi:10.1207/ S15327752JPA7901_04

Salovey, P., Mayer, J. D., Goldman, S. L., Turvey, C., \& Palfai, T. P. (1995). Emotional attention, clarity, and repair: Exploring emotional intelligence using the Trait Meta-Mood Scale. In J. W. Pennebaker (Ed.), Emotion, disclosure, and health (pp. 125-154). Washington, DC: American Psychological Association.

Saulsman, L. M., \& Page, A. C. (2004). The five-factor model and personality disorder empirical literature: A meta-analytic review. Clinical Psychology Review, 23(8), 1055--1085.

Schmitz, N., Kugler, J., \& Rollnik, J. (2003). On the relation between neuroticism, self-esteem, and depression: Results from the National Comorbidity Survey. Comprehensive Psychiatry, 44, 169-176.

Silvia, P. J., \& Kwapil, T. R. (2011). Aberrant asociality: How individual differences in social anhedonia illuminate the need to belong. Journal of Personality, 79(6), 1315-1332. doi:10.1111/j.1467-6494.2010.00702.x

Stemberger, R. T., Turner, S. M., Beidel, D. C., \& Calhoun, K. S. (1995). Social phobia: An analysis of possible developmental factors. Abnormal Psychology, 104(3), 526-531.

Strauss, G. P., \& Gold, J. M. (2012). A new perspective on anhedonia in schizophrenia. American Journal of Psychiatry, 169(4), 364-373. doi:10.1176/appi.ajp.2011.11030447

Tarbox, S. I., Addington, J., Cadenhead, K. S., Cannon, T. D., Cornblatt, B. A., Perkins, D. O., . . Woods, S. W. (2013). Premorbid functional development and conversion to psychosis in clinical high-risk youths. Development and Psychopathology, 25(4, Pt. 1), 1171-1186. doi:10.1017/S0954579413000448

Timoney, L. R., \& Holder, M. D. (2013). Alexithymia and personality. In Emotional processing deficits and happiness: Assessing the measurement, correlates, and well-being of people with alexithymia (pp. 61-68). New York, NY: Springer.

Whitton, S. W., \& Kuryluk, A. D. (2013). Intrapersonal moderators of the association between relationship satisfaction and depressive symptoms: Findings from emerging adults. Journal of Social and Personal Relationships, 30, 750-770.

Widiger, T., \& Smith, G. (2008). Personality and psychopathology. In O. John, R. Robins, \& L. Pervin (Eds.), Handbook of personality: Theory and research (3rd ed., 743-769). New York, NY: Guilford. 